\title{
A comparison of the Medieval Warm Period, Little Ice Age and 20th century warming simulated by the FGOALS climate system model
}

\author{
ZHOU TianJun $^{1 *}$, LI Bo $^{1,2}$, MAN WenMin ${ }^{1,2}$, ZHANG LiXia $^{1,2} \&$ ZHANG Jie ${ }^{1,2}$ \\ ${ }^{1}$ The State Key Laboratory of Numerical Modeling for Atmospheric Sciences and Geophysical Fluid Dynamics, Institute of Atmospheric Physics, \\ Chinese Academy of Sciences, Beijing 100029, China; \\ ${ }^{2}$ The Graduate University of Chinese Academy of Sciences, Beijing 100049, China
}

Received March 7, 2011; accepted June 16, 2011

To compare differences among the Medieval Warm Period (MWP), Little Ice Age (LIA), and 20th century global warming $(20 \mathrm{CW})$, six sets of transient and equilibrium simulations were generated using the climate system model FGOALS_gl. This model was developed by the State Key Laboratory of Numerical Modeling for Atmospheric Sciences and Geophysical Fluid Dynamics, Institute of Atmospheric Physics, Chinese Academy of Sciences. The results indicate that MWP warming is evident on a global scale, except for at mid-latitudes of the North Pacific. However, the magnitude of the warming is weaker than that in the 20th century. The warming in the high latitudes of the Northern Hemisphere is stronger than that in the Southern Hemisphere. The LIA cooling is also evident on a global scale, with a strong cooling over the high Eurasian continent, while the cooling center is over the Arctic domain. Both the MWP and the $20 \mathrm{CW}$ experiments exhibit the strongest warming anomalies in the middle troposphere around $200-300 \mathrm{hPa}$, but the cooling center of the LIA experiment is seen in the polar surface of the Northern Hemisphere. A comparison of model simulation against the reconstruction indicates that model's performance in simulating the surface air temperature changes during the warm periods is better than that during the cold periods. The consistencies between model and reconstruction in lower latitudes are better than those in high latitudes. Comparison of the inter-annual variability mode of East Asian summer monsoon (EASM) rainfall during the MWP, LIA and 20CW reveals a similar rainfall anomalies pattern. However, the time spectra of the principal component during the three typical periods of the last millennium are different, and the quasi-biannual oscillation is more evident during the two warm periods. At a centennial time scale, the external mode of the EASM variability driven by the changes of effective solar radiation is determined by the changes of large scale land-sea thermal contrast. The rainfall anomalies over the east of $110^{\circ} \mathrm{E}$ exhibit a meridional homogeneous change pattern, which is different from the meridional out-of-phase change of rainfall anomalies associated with the internal mode.

Medieval Warm Period, Little Ice Age, 20th century warming, coupled climate system model, temperature changes, East Asian summer monsoon

Citation: Zhou T J, Li B, Man W M, et al. A comparison of the Medieval Warm Period, Little Ice Age and 20th century warming simulated by the FGOALS climate system model. Chinese Sci Bull, 2011, 56: 3028-3041, doi: 10.1007/s11434-011-4641-6

Global warming is of great concern to the climate change research community. To achieve a better understanding of the 20th century global warming, it is important to extend our temporal scale of investigation from the past century to the past millennium. Evolution of climate over the past millennial includes three typical periods (i.e. the Medieval

*Corresponding author (email: zhoutj@lasg.iap.ac.cn)
Warming Period [A.D. 900-1300, hereafter MWP], the Little Ice Age [A.D. 1550-1850, hereafter LIA], and the 20th century global warming [hereafter $20 \mathrm{CW}]$ ) [1]. These three typical periods are driven by different forcing agents. The MWP and LIA climate represent natural variability due to changes in solar variability and volcanic eruptions. There were less (more) volcanic eruptions but more (less) solar radiation input during the MWP (LIA). Evidence suggests 
that the 20th century warming is resulted from the increased anthropogenic greenhouse gas (GHG) emissions [2].

Studies on climate change over the past millennium rely on either climate reconstruction [3,4] or climate modeling [5]. Climate reconstruction can reveal the observational features of the past climate changes, while climate modeling helps us understand the mechanisms of the past and future climate change. Previous modeling studies usually focused on specific periods, such as the LIA, and always employed uncoupled offline Atmospheric General Circulation Models (AGCM) [6,7]. In the offline AGCM simulations, the feedback of ocean to atmospheric forcing is absent, and thus reliability of the simulations is limited.

Coupled climate system models include both atmospheric and oceanic components, as well as land surface and sea ice components, and have developed rapidly in recent years. Coupled climate system models have been playing essential roles in simulating and understanding the past climate changes [8]. To improve the understanding of the 20th century global warming, the Working Group on Coupled Modeling (WGCM) of the World Climate Research Program (WCRP) has organized a project entitled "The 20th century Climate in Coupled Models" (20C3M), in which the 20th century climate simulations were made with various combinations of forcing agents, including GHGs, sulfate aerosols, ozone, volcanic aerosols and solar variabilities. Analysis of the outputs of $20 \mathrm{C} 3 \mathrm{M}$ models indicate that most models have a reasonable performance in reproducing the evolution of both the global and northern hemispheric mean surface air temperatures (SAT) of the 20th century. The reproducibility of regional scale SAT change, such as China, is lower than that of the global and hemispheric averages, but is still acceptable $[9,10]$.

Because of the expensive computation costs, long-term simulation of the past millennial climate only began in recent years [11-15]. However, in comparison with the 20th century global warming simulation, a successful simulation of the past millennial climate change is technically more difficult, which is due to that during the natural variability periods, such as the MWP and LIA, the changes of external forcing agents (i.e. effective solar radiation) are weaker than those of the forcing agents (e.g. GHGs) during the 20th century. A successful simulation of the past climate changes depends on the model's sensitivity to the prescribed external forcing. The relative weak change of external forcings during the MWP and LIA challenges the current generation of state-of-the-art climate models. When driven by identical external forcing agents, models' response may be different from each other depending on the different model sensitivities.

To better understand the position of 20th century climate warming during the evolution of the past millennial climate, and to reduce uncertainties of the simulations based on specific models, the Coupled Model Inter-comparison Project-Phase 5 (CMIP5) has promoted an international collab- oration of the past millennial climate simulation. This simulation is part of WGCM modeling activities for the 5th assessment report (AR5) of the Intergovernmental Panel on Climate Change (IPCC). Under this coordination, many climate modeling centers around the world will release their data for the past millennial climate simulation by the end of 2012. Supported by the National Natural Science Foundation of China under the program "Climate reconstruction based on tree-rings in China and the past millennial climate changes studies", the State Key Laboratory of Numerical Modeling for Atmospheric Sciences and Geophysical Fluid Dynamics (LASG), Institute of Atmospheric Physics, Chinese Academy of Sciences (hereafter LASG/IAP), has been involved in the past millennial climate simulations coordinated by CMIP5. The LASG/IAP climate system model FGOALS_gl is used in the past millennial climate simulation. Based on the outputs of FGOALS_gl, the current study aims to answer the following questions: (1) What are the differences in temperature changes among the MWP, LIA and $20 \mathrm{CW}$ in the past millennial climate simulation? (2) How dose the coupled model response to the natural and anthropogenic forcing agents? (3) Are there any differences in the transient and equilibrium simulations for the MWP and LIA climate? (4) What is the difference between external mode and internal mode of the East Asian summer monsoon variability?

\section{Model, numerical experiments and data description}

The model used in the current study is FGOALS_gl [19], which is a fast-coupled version of the normal version of LASG/IAP "Flexible-Global-Ocean-Atmosphere-Land Surface-Sea Ice" coupled model FGOALS [16-18]. The fourcomponent models are joined together using the NCAR CCSM2 coupler. The AGCM component of FGOALS_gl is the Grid Atmospheric Model of LASG/IAP (GAMIL), which employs a horizontal resolution of $5.0^{\circ}$ (longitude) $\times$ $4.0^{\circ}$ (latitude). The model vertically employs a sigma-pressure coordinate, and there are 26 vertical levels. The oceanic component of the coupled model is LASG/IAP climate ocean model (LICOM), which was developed based on the 3rd generation of LASG/IAP Oceanic General Circulation Mode (OGCM) L30T63. The horizontal resolution of LICOM used here is $1^{\circ} \times 1^{\circ}$, and there are 30 levels in the vertical direction. The land surface and sea ice components of the coupled model are NCAR CLM and CSIM, respectively. Note that the coupled model does not employ flux correction techniques. Details of the model are described in the references $[19,20]$. Previous studies have found that the model has a reasonable performance in simulating 20th century climate [10].

In this study, both the equilibrium and transient simulations were performed in the MWP, LIA and $20 \mathrm{CW}$ climate 
simulations. In the equilibrium simulation, the external forcing agents (effective solar radiation) and the atmospheric composition (GHGs and aerosols) were set to the average of a specific time period (i.e. there was no year-by-year variation in the prescribed forcing data). In the transient simulation, both the external forcing agents and the atmospheric composition were prescribed yearly (i.e. there is a robust year-by-year variation).

Seven sets of numerical simulations are conducted in this study. The details are described below:

(1) Pre-industrial control run (1860CTL). The solar constant is set to $1365 \mathrm{~W} / \mathrm{m}^{2}$, and the GHGs are set as $\mathrm{CO}_{2}=$ 280.0 ppmv, $\mathrm{CH}_{4}=760.0$ ppbv, $\mathrm{N}_{2} \mathrm{O}=270.0$ ppbv. A one thousand-year integration is performed, and the final 30 years are used in the analysis.

(2) Equilibrium simulation of the MWP (MWP-E). The solar constant is set to $1367 \mathrm{~W} / \mathrm{m}^{2}$, and the GHGs are set as $\mathrm{CO}_{2}=289.6$ ppmv, $\mathrm{CH}_{4}=760.0$ ppbv, $\mathrm{N}_{2} \mathrm{O}=270.0$ ppbv. Eighty year simulations are performed, and the final 30 years are used in the analysis.

(3) Equilibrium simulation of the LIA (LIA-E). The solar constant is set to $1363 \mathrm{~W} / \mathrm{m}^{2}$, and the GHGs ae set as $\mathrm{CO}_{2}=$ 289.6 ppmv, $\mathrm{CH}_{4}=760.0$ ppbv, $\mathrm{N}_{2} \mathrm{O}=270.0$ ppbv. Eighty year simulations are conducted, and the final 30 years are used in the analysis.

(4) Equilibrium simulation of the 20CW (20C-E). The solar constant was set to $1365 \mathrm{~W} / \mathrm{m}^{2}$, and the GHGs are set as: $\mathrm{CO}_{2}=355.6$ ppmv, $\mathrm{CH}_{4}=760.0$ ppbv, $\mathrm{N}_{2} \mathrm{O}=270.0$ ppbv. Eighty year simulations are performed.

(5) Transient simulation of the MWP (MWP-T). The initial condition begins from January of the 80th year of the MWP-E integration. The reconstructed changes of solar constants and volcanic eruptions are transformed to effective solar radiation, and used to drive the model [21]. The changes of atmospheric compositions, including $\mathrm{CO}_{2}, \mathrm{CH}_{4}$, and $\mathrm{N}_{2} \mathrm{O}$, are those used in the past millennial simulation of NCAR-CSM1.4. The changes of effective solar radiation and GHGs during the past millennium are shown in Figure 1. The model simulation covers the core time period of the MWP (i.e. AD 1100-AD 1200).

(6) Transient simulation of the LIA (LIA-T). The initial condition begins in January of the 80th year of the LIA-E integration. The effective solar radiation data are from Crowley [21], and the atmospheric composition data are from NCAR [44]. The changes of effective solar radiation and atmospheric composition are shown in Figure 1, and are used to drive the model. The simulation covers the core period of the LIA (i.e. AD 1650 - AD 1750). As shown in Figure 1, the LIA is forced by a lower effective solar radiation.

(7) Transient simulation of the $20 \mathrm{CW}(20 \mathrm{CW}-\mathrm{T})$. The forcing data are from CMIP3 for IPCC AR4. The changes of both natural agents (solar constant and volcanic aerosols) and anthropogenic agents (greenhouse gases and sulfate aerosols) are described in [9]. The change of atmospheric

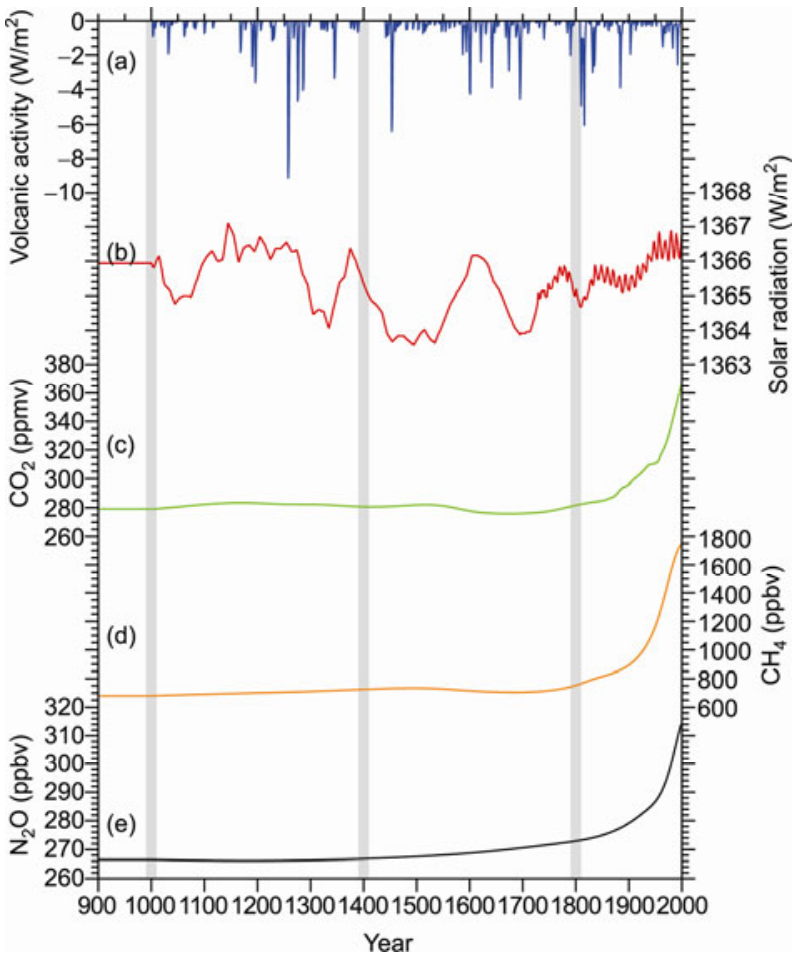

Figure 1 Time series of forcing data used in the past millennial climate simulation. Volcanic eruptions (blue, w/ $/ \mathrm{m}^{2}$ ), solar activity (red, w/m $\left./ \mathrm{m}^{2}\right), \mathrm{CO}_{2}$ (green, ppmv), and $\mathrm{N}_{2} \mathrm{O}$ (black, ppbv).

composition in the 20th century exhibits an increase of GHGs (Figure 1). The simulation covers the period of 1860 to 2000 .

Note that the effective solar radiation of LIA-E (MWP-E) experiment is $2 \mathrm{~W} / \mathrm{m}^{2}$ less (more) than that of the 1860CTL experiment. This specified anomalous value is based on the reconstructions that account for the changes of solar constant and volcanic eruptions. The parameters of the numerical experiments are summarized in Table 1.

The following reconstruction data are used to validate the model results:

(1) The reconstructed SAT changes during the past millennium in 30 stations around the world. The reconstruction was based on tree-ring, ice-core, historical documentary, sporopollen, stalagmite, and glacier records [1].

(2) The monthly precipitation data of CMAP (CPC Merged Analysis of Precipitation) [22].

\section{Results}

\subsection{Horizontal and vertical distributions of the temperature changes}

The annual mean SAT anomalies simulated by the six sets of experiments relative to the 1860CTL run are shown in Figure 2. During the MWP period, both the tropical and subtropical regions are dominated by warming anomalies, except for the equatorial eastern Pacific. A warming center 
Table 1 Greenhouse gas parameters and solar radiation used in the modeling experiments

\begin{tabular}{lcccc}
\hline Experiments & $\mathrm{CO}_{2}(\mathrm{ppmv})$ & $\mathrm{N}_{2} \mathrm{O}(\mathrm{ppbv})$ & $\mathrm{CH}_{4}(\mathrm{ppbv})$ & Solar radiation $\left(\mathrm{W} / \mathrm{m}^{2}\right)$ \\
\hline 1860CTL & 280.0 & 270 & 760 & 1365 \\
MWP-E & 289.6 & 270 & 760 & 1367 \\
LIA-E & 289.6 & 270 & 760 & 1363 \\
20C-E & 355.6 & 270 & 760 & 1365 \\
MWP-T & NCAR & NCAR & NCAR & CROWLEY2000 \\
LIA-T & NCAR & NCAR & AR4 & CROWLEY2000 \\
20C-T & AR4 & AR4 & AR4 \\
\hline
\end{tabular}

NCAR denotes the external forcing data used in the past millennial climate simulation of NCAR [44]. AR4 denotes the forcing data used in the 20th century climate simulation coordinated by CMIP3 for IPCC AR4. CROWLEY2000 denotes that the solar radiation data are from Crowley [21].

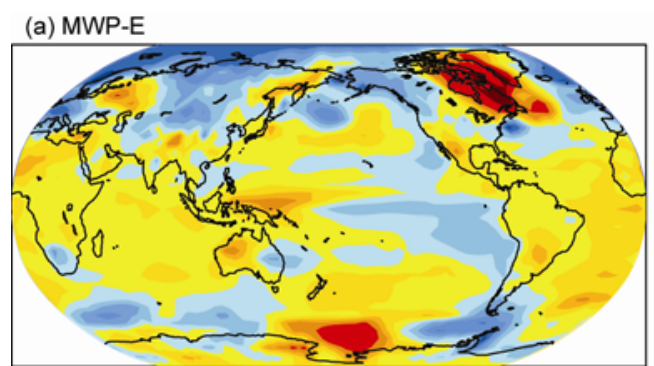

(b) MWP-T

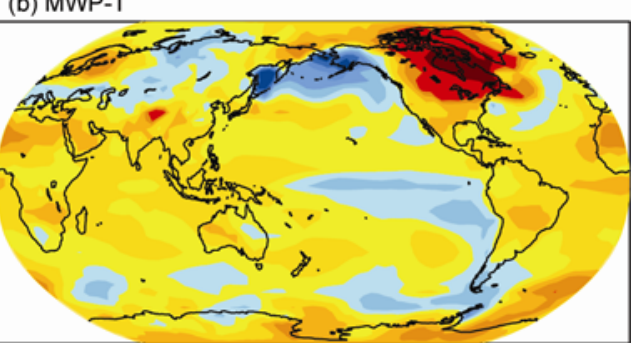

(d) LIA-T

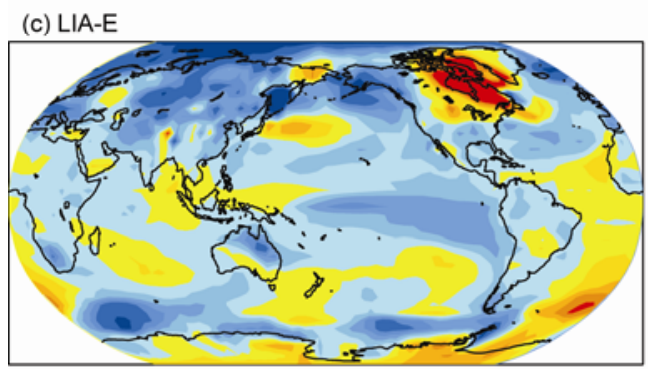

(e) $20 \mathrm{CW}-\mathrm{E}$

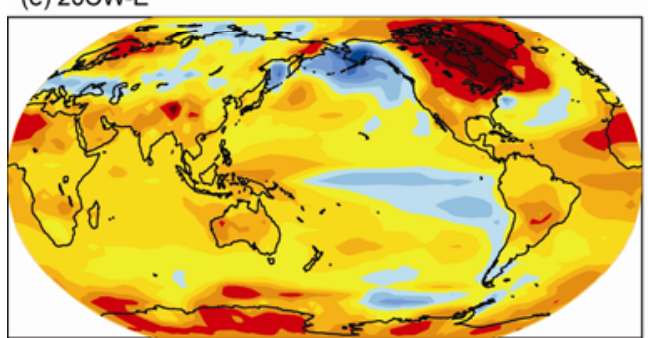

(f) $20 \mathrm{CW}-\mathrm{T}$
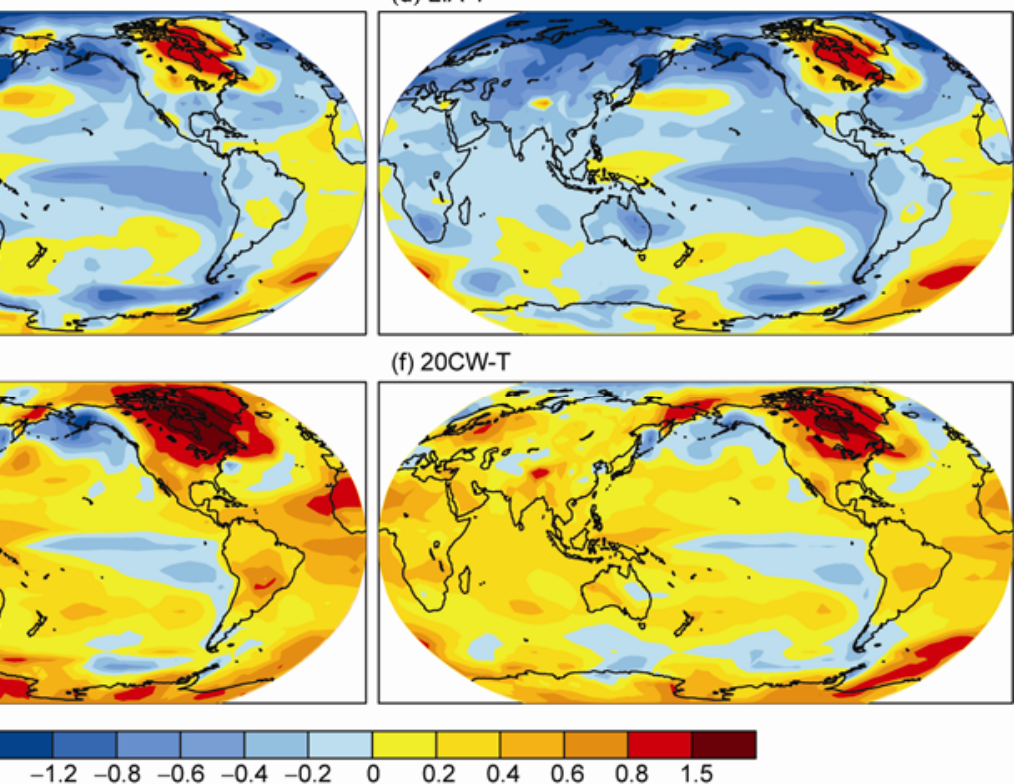

Figure 2 Annual mean surface air temperature anomalies of three typical time periods of the last millennium relative to the pre-industrial control run (Unit: $\left.{ }^{\circ} \mathrm{C}\right)$.

is evident in the high latitudes of North America, while cold anomalies are seen in the high latitudes of the Eurasian continent. Natural warming during the MWP is generally weaker in magnitude than that in the 20th century warming. The latter is more evident over a global scale. The natural cooling of the LIA is also seen at a global scale, but the high latitudes of the North American continent reflect warmer anomalies. The Atlantic domain features a dipole pattern, with cold (warm) anomalies located at the north (south) of the equator.
Differences are seen between the equilibrium and transient simulations, particularly in the MWP and LIA periods. For example, the natural warming of the MWP-T experiment is more evident in its spatial pattern and the stronger magnitude than in the MWP-E experiment. The cold anomalies of the LIA-T experiment are also stronger than those in the LIA-E experiment. In addition, warm anomalies are seen in the high latitudes of North America in all sets of the MWP, LIA and $20 \mathrm{CW}$ experiments. A further examination finds that this is due to the cold bias of SAT in the preindus- 
trial control run (figures not shown).

The equatorial eastern Pacific features cold anomalies in the MWP, LIA and 20CW experiments. The magnitude of the cold anomalies is the strongest in the LIA experiment. Previous studies have shown that sea surface temperature changes in the equatorial eastern Pacific are dominated by the ocean dynamical processes rather than the thermal processes [10]. The cold anomalies are the result of an enhanced trade wind and the associated stronger upwelling of subsurface cold water [14]. Because of the dominance of dynamical rather than the thermal processes, it is a challenge to for the current state-of-the-art coupled climate system models to accurately simulate surface temperature changes of the equatorial eastern Pacific [23].

To reveal the vertical structure of temperature changes, the meridional-vertical cross sections of zonal mean temperature anomalies of the MWP, LIA and $20 \mathrm{CW}$ relative to the 1860CTL are shown in Figure 3. The MWP and 20CW experiments feature similar vertical patterns, with the warming center located around 200-300 hPa (Figure 3(a), (b), (e), (f)). However, the natural warming of the MWP is significantly weaker than that in the $20 \mathrm{CW}$, with a central value of $0.50^{\circ} \mathrm{C}$ for the MWP versus $1.0^{\circ} \mathrm{C}$ for the $20 \mathrm{CW}$. The vertical pattern of LIA exhibits a polar amplification, with a cooling center in the high latitudes.

Differences are seen between the equilibrium and transient simulations. The temperature anomalies of the MWP and LIA simulated by the transient experiments are generally stronger than those in the equilibrium experiments, except for the high latitudes in the LIA experiment. For example, the tropical warming of the MWP-T exhibits a central value of $0.50^{\circ} \mathrm{C}$, and around $200-300 \mathrm{hPa}$. However, the corresponding change of MWP-E is only $0.30^{\circ} \mathrm{C}$.

Why do both the MWP and 20CW experiments exhibit a mid-tropospheric amplification response to the temperature changes? Previous studies have revealed that the energy balance of tropospheric temperature is determined by the longwave radiation cooling and convective heating [24]. In the $20 \mathrm{CW}$ experiment, the increased GHGs lead to an increase of net longwave radiation input and thereby a warming tendency of surface air temperature. The warming surface promotes more frequent convection. Convective heating is stronger than radiation cooling and, thus, results in the warming anomalies in the troposphere. Since the condensation of water vapor associated with convection peaks in the middle troposphere, the center of tropospheric warming appears in the middle troposphere around $200-300 \mathrm{hPa}$. In the MWP experiment, the increase of effective solar radiation
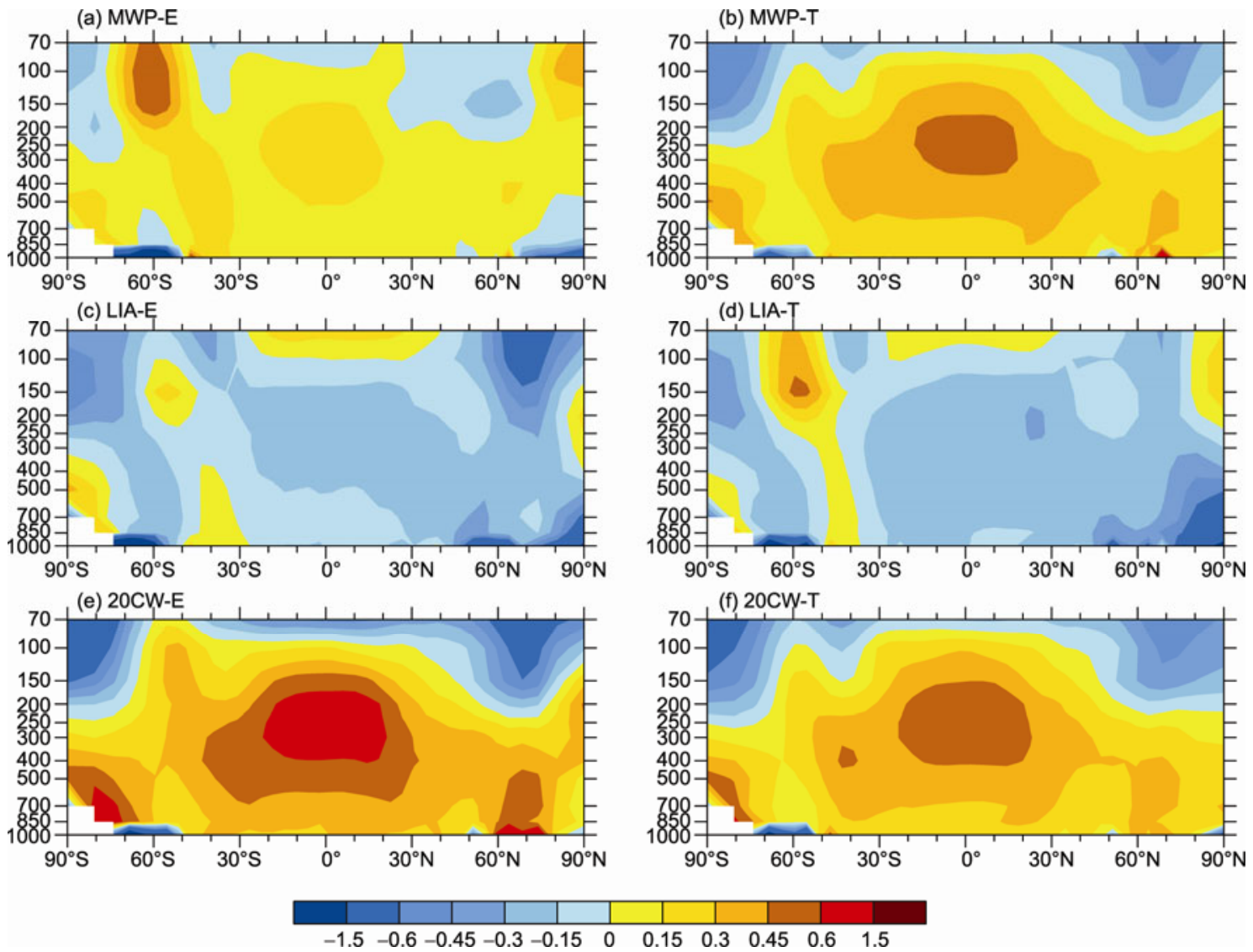

Figure 3 Vertical-meridional cross-sections of annual zonal mean temperature anomalies of three typical time periods of the last millennium relative to the pre-industrial control run (Unit: $\left.{ }^{\circ} \mathrm{C}\right)$. 
results in warmer anomalies of SAT and more frequent convections, and thereby produces a warming center around 200-300 hPa. Thus, the mid-tropospheric amplification of temperature change seen in the MWP and 20CW experiments can be explained by the radiation-convection feedback model [24].

\subsection{Latitude-dependence of the temperature changes}

Temperature changes are different along different latitudes. To verify the performance of the model in simulating the SAT changes along different latitudes, model results are compared with the reconstructions at 30 sites throughout the world. The reconstruction data are from Wang et al. [1]. In Figure 4, the SAT changes derived from transient simulations were compared with the reconstruction. The 30 sites are sorted from the north to the south based on their latitudes. Since it is still a challenge to quantitatively compare the magnitude of simulated temperature changes with the reconstructions, partly because of the uncertainties in the reconstructions, we compare the "same-sign-rate" between the simulation and the reconstruction here. As shown in Figure 4 , the $20 \mathrm{CW}-\mathrm{T}$ experiment has the highest samesign-rate, followed by the MWP-T and LIA-T experiments. If the reconstruction is reliable, results suggest that the performance of the current state-of-the-art coupled climate models in simulating the warm climate periods is better than that in the cold periods. Whether the result is model-dependent deserves further study.

In addition, the same-sign-rate between the simulation and the reconstruction in the tropical and subtropical regions is higher than that in the high latitudes. This applies to both the MWP and LIA experiments. In the MWP and $20 \mathrm{CW}$ period, both the reconstruction and the observation show that the magnitude of temperature changes in high latitudes of the northern hemisphere is larger than that in the Southern Hemisphere (Figure 4(a), (c)). The difference is also evident in the simulation.

To better understand the latitude-dependence of temperature changes, the time evolution of annual zonal mean temperature changes simulated by the transient simulations are shown in Figure 5. The strongest warming of the MWP-T experiment appears in A.D. 1160 and A.D. 1180 with a magnitude of about $1{ }^{\circ} \mathrm{C}$ (Figure 5(a)). The time of the warming peak corresponds well to the maximum of the prescribed effective solar radiation (Figure 1). The latitude-dependence of temperature changes exhibits a polar-amplification phenomenon due to snow ice-albedo feedback in the high latitudes. The warming in the $20 \mathrm{CW}-\mathrm{T}$ experiment is the most evident after the 1970s and also exhibits a polar-amplification phenomenon with a maximum of about $1.0^{\circ} \mathrm{C}$ (Figure 5(c)), and this characteristic is consistent with instrumental observations [25]. The LIA-T experiment also exhibits a similar polar-amplification phenomenon, but the cooling is the most evident in the northern hemisphere. The
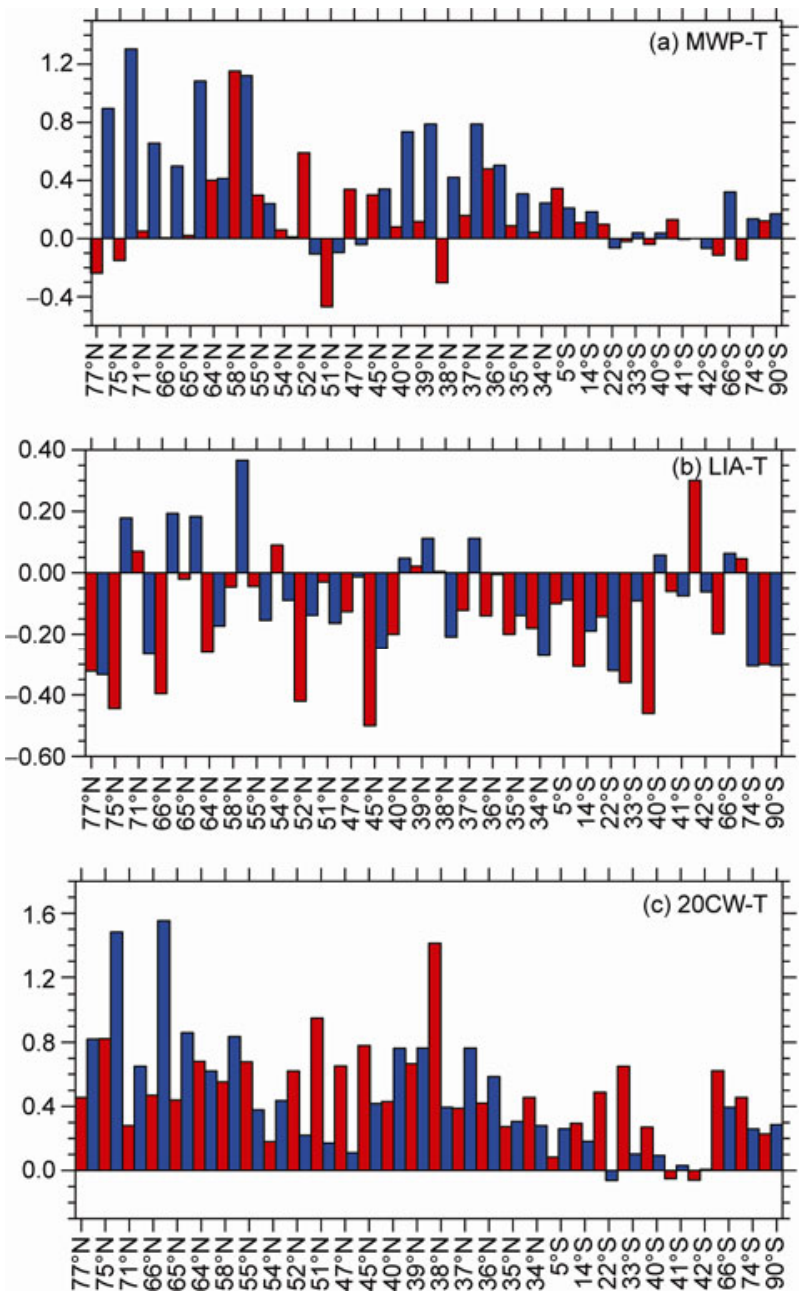

Figure 4 The reconstructed (red) and simulated (blue) surface air temperature anomalies of three typical time periods of the last millennium at 30 sites around the world, sorted from north to south, and based on their latitudes. (a) MWP-T; (b) LIA-T (redrawn based on [14]); (c) 20CW-T (Unit: ${ }^{\circ} \mathrm{C}$ ).

cooling in the tropical region is not significant, and the Southern Hemisphere even exhibits weak regional scale warming anomalies (Figure 5(b)).

The above discussions with respect to the data shown in Figures 3 and 5 indicate that both the MWP and 20CW experiments exhibit a polar-amplification phenomenon due to the positive snow-albedo feedback in the high latitudes. Because of the dominance of the convective heating, the tropospheric temperature change peaks in the middle troposphere around 200-300 hPa. The surface temperature changes in the LIA period also exhibit a polar amplification in the northern hemisphere, but the cooling is the strongest in the lower troposphere rather than the middle troposphere, as in the MWP and 20CW experiments.

\subsection{Precipitation changes}

The annual mean precipitation anomalies simulated by 6 sets of experiments are shown in Figure 6. The anomalies 

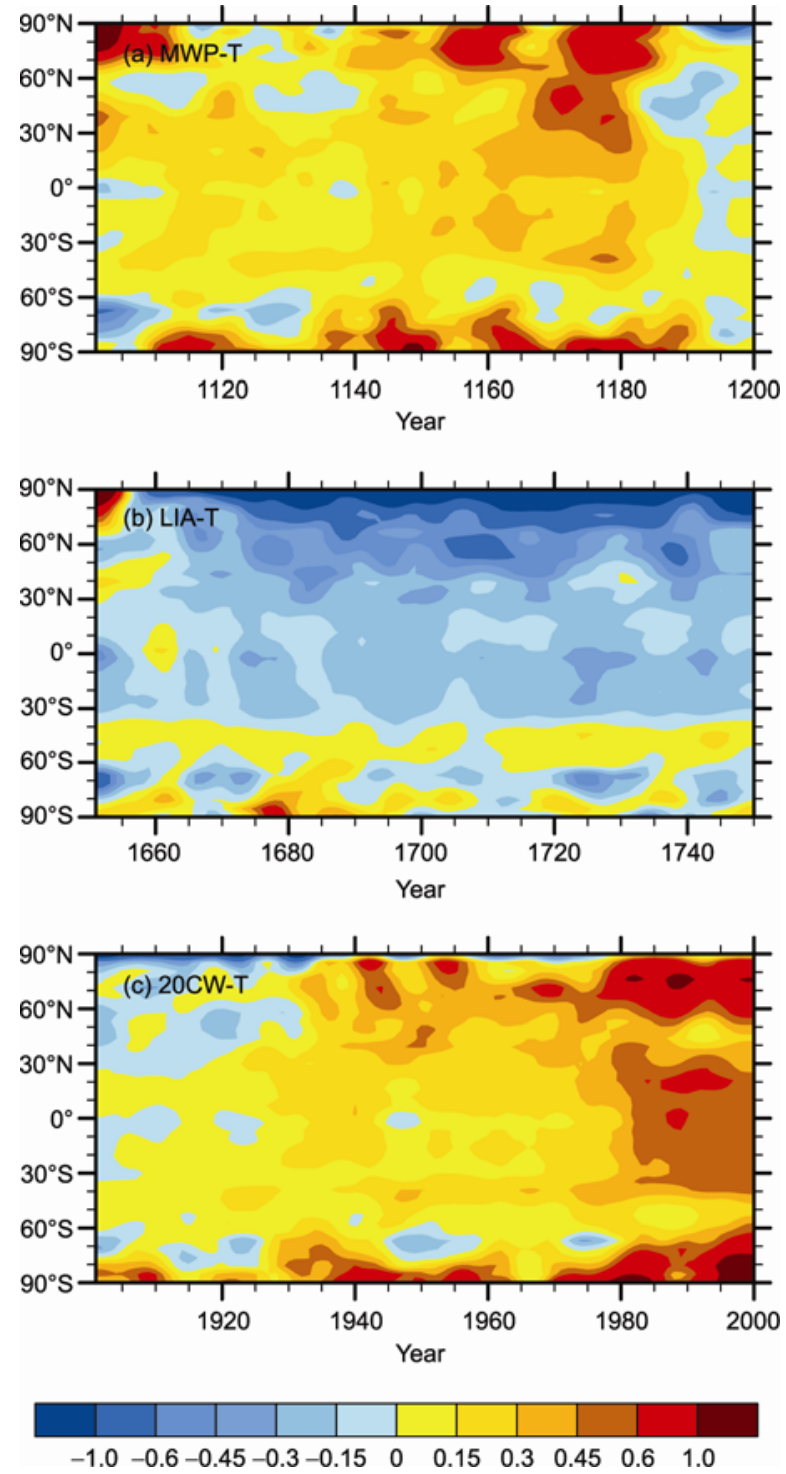

Figure 5 Evolution of simulated annual zonal mean surface air temperature anomalies of three typical time periods of the last millennium relative to the pre-industrial control run (Unit: ${ }^{\circ} \mathrm{C}$ ).

are calculated relative to the normal 1860CTL run. Both the equilibrium experiments (Figure 6(a), (c), (e)) and transient simulations (Figure 6(b), (d), (f)) exhibit a strongest precipitation response in the tropics. The pattern of precipitation anomalies corresponds well to that of temperature anomalies shown in Figure 2. For example, alike the zonal out-ofphase change of tropical temperatures, the precipitation response also features an out-of-phase change, with the suppressive rainfall east to the dateline, but excessive rainfall west to the dateline. Note that the increase of precipitation west to the dateline during the MWP and $20 \mathrm{CW}$ is stronger in magnitude than the decrease of precipitation east to the dateline (Figure 6(a), (b), (e), (f)). The excessive tropical precipitation change results in stronger convective heating, and thereby central warming anomalies around 200-300 hPa in the tropical troposphere. Because of the fact that the increase of tropical precipitation during the $20 \mathrm{CW}$ is stronger than that during the MWP (Figure 6), the middle troposphere warming in the $20 \mathrm{CW}$ experiment is stronger than that in the MWP. The above features are more evident in the MWP-E and 20CW-E experiments. In addition, negative precipitation anomales are seen in the equatorial eastern Pacific, as a response to the colder sea surface temperature (SST) in the LIA experiments.

The time evolution of annual mean zonal precipitation changes are shown in Figure 7. The tropical precipitation change features a dipole pattern in the meridional direction, with negative values along the equator. According to Figure 6 , this pattern is dominated by deficient rainfall along the equatorial eastern Pacific. The precipitation change exhibits positive anomalies along $10^{\circ} \mathrm{N}$, with stronger amplitude in the MWP and $20 \mathrm{CW}$ experiments. The precipitation response to the LIA experiment is more evident along the equatorial Pacific with negative centers. The extra-tropical precipitation response is stronger in the cold climate period (Figure 7(b)). For example, the decrease of precipitation north to $60^{\circ} \mathrm{N}$ is more evident in the LIA experiment, but is not significant in the MWP experiment.

Note that the precipitation change has robust regional patterns. The zonal mean changes shown above only provide a first-order gross examination. In the following section, we focus on the changes of the East Asian summer monsoon.

\subsection{Changes of the inter-annual leading mode of the EASM rainfall}

The annual mean precipitation over East Asia simulated by the model is compared with the observational data in Figure $8(\mathrm{a})$, (b). In the observation, precipitation decreases from southeast to northwest, and there is an artificial rainfall center in the eastern periphery of the Tibetan Plateau around $100^{\circ} \mathrm{E}, 30^{\circ} \mathrm{N}$, with a central intensity of $7 \mathrm{~mm} / \mathrm{d}$. This bias is normally evident in many low resolution climate models, partly because of the treatment of steep topography in the model. The calculation of pressure gradient forcing in the steep topography areas usually shows large biases [26,27], which may further impact the rainfall simulations. Similar rainfall bias also can be seen in the National Center for Atmospheric Research (NCAR) model CCM3.5 [28], CAM3 [29], and a French model LMDZ AGCM [30,31].

East Asian precipitation exhibits a robust seasonal cycle associated with monsoon development. The seasonal cycles of extra-tropical $\left(36^{\circ}-50^{\circ} \mathrm{N}, 100^{\circ}-120^{\circ} \mathrm{E}\right)$ and subtropical $\left(21^{\circ}-35^{\circ} \mathrm{N}, 100^{\circ}-120^{\circ} \mathrm{E}\right)$ precipitation are shown in Figures 8(c), (d). In the extra-tropical East Asia (Figure 8(c)), the simulation is about $2.0 \mathrm{~mm} / \mathrm{d}$ stronger than the observation, but the seasonal peak is about one month later than the observation. In the subtropical East Asia (Figure 8(d)), the simulation resembles the observation in intensity, but the seasonal peak lags the observation by about 2-3 months. 

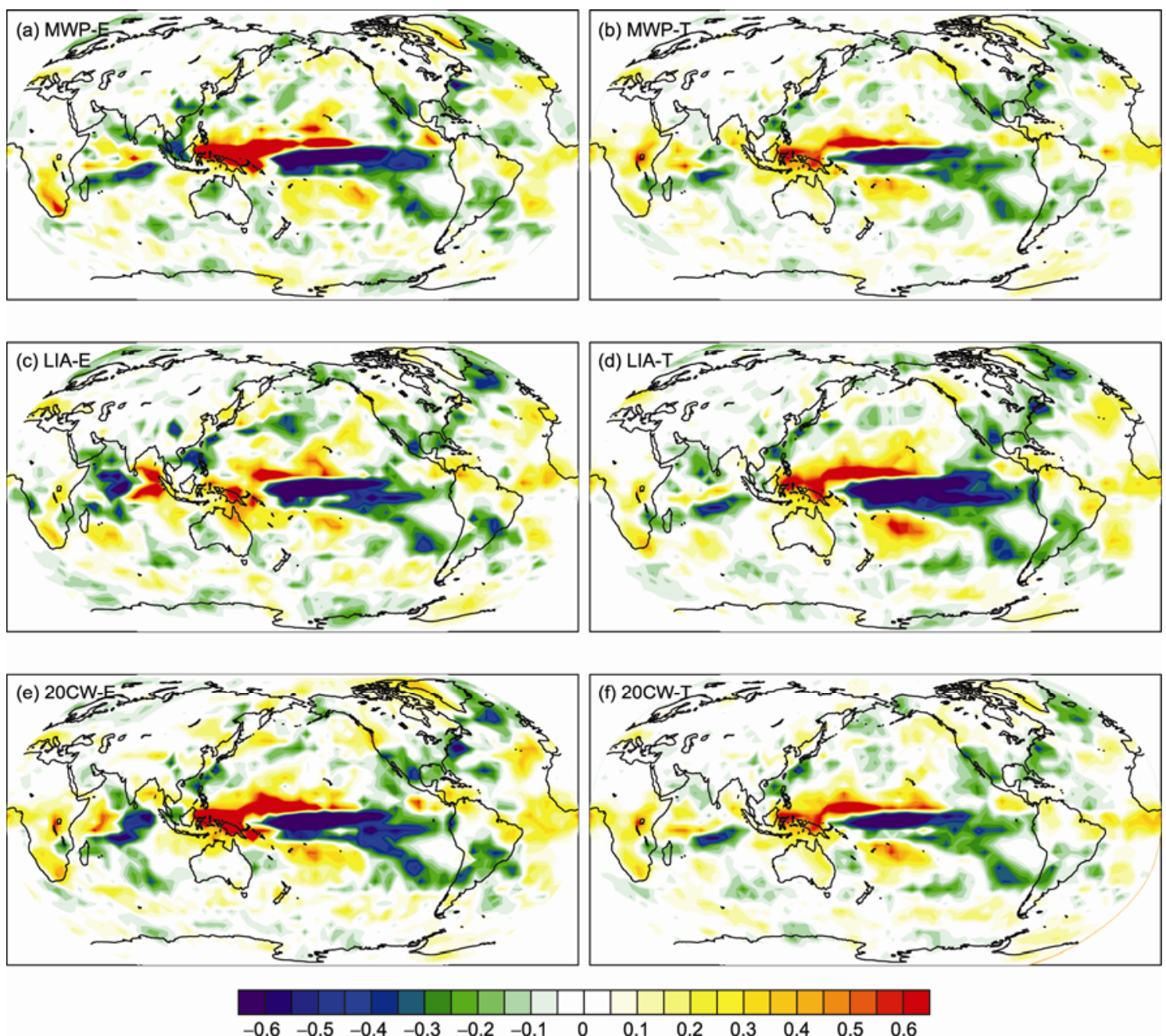

Figure 6 Simulated annual mean precipitation anomalies of three typical time periods of the last millennium relative to the pre-industrial control run (Unit: mm/d).
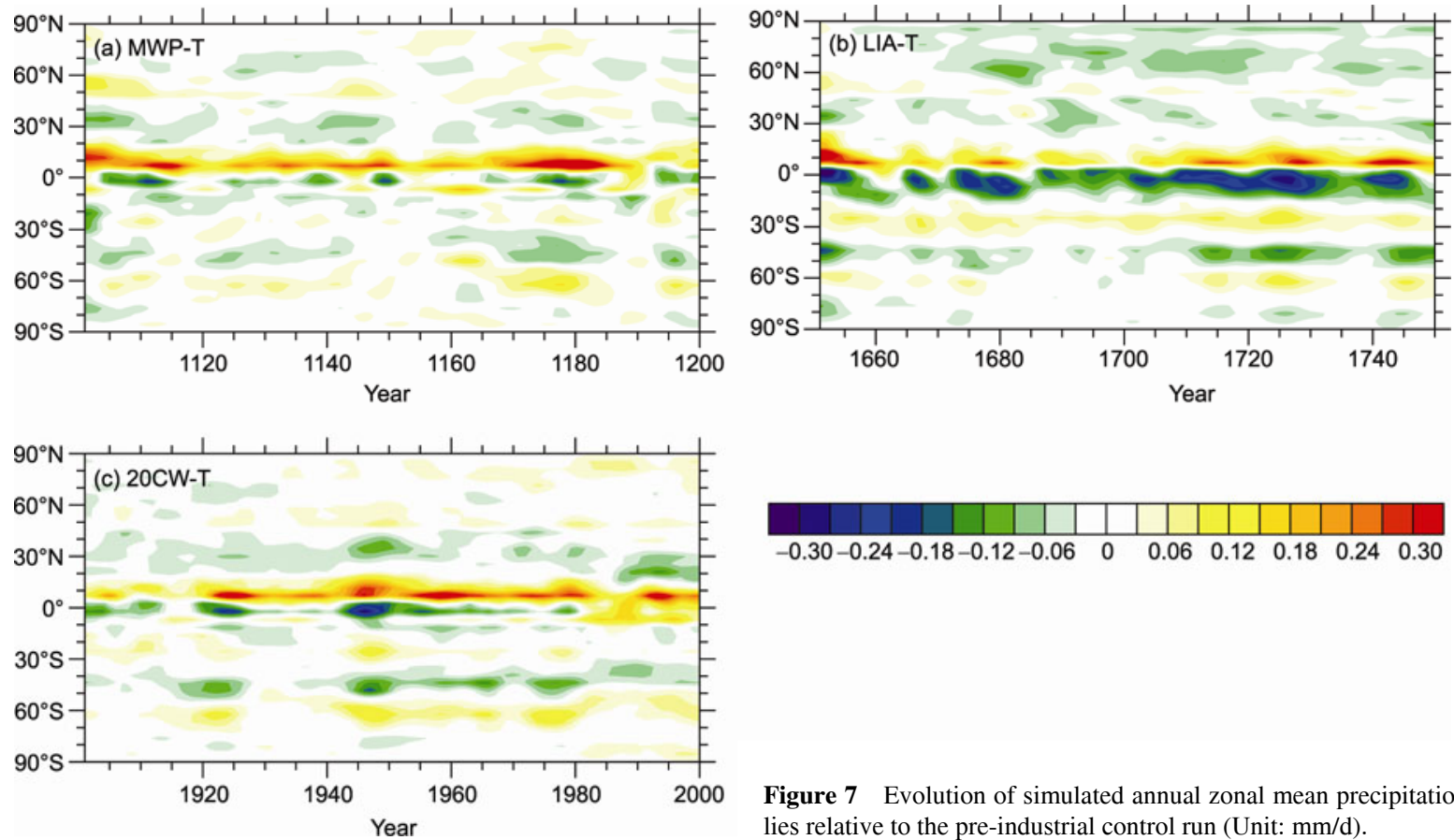

Figure 7 Evolution of simulated annual zonal mean precipitation anomalies relative to the pre-industrial control run (Unit: $\mathrm{mm} / \mathrm{d}$ ). 

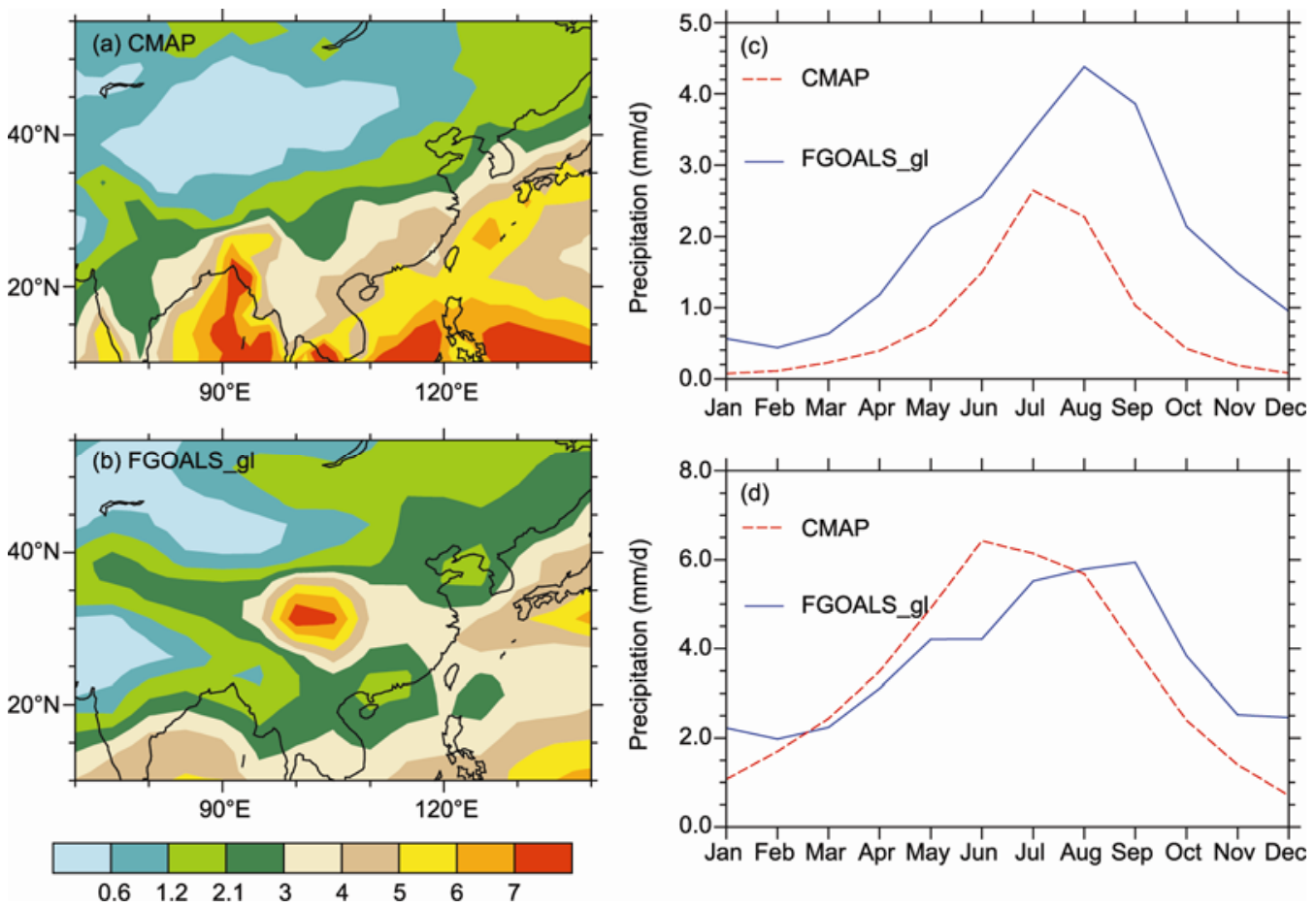

Figure 8 The annual mean distribution and seasonal cycle of precipitation in the observation and the simulation. (a) Annual mean of CMAP data during 1979-2000; (b) 20CW-T simulation; (c) seasonal cycle of regional $\left(36^{\circ}-50^{\circ} \mathrm{N}, 100^{\circ}-120^{\circ} \mathrm{E}\right)$ average of precipitation; (d) seasonal cycle of regional (21 ${ }^{\circ}-35^{\circ} \mathrm{N}$, $\left.100^{\circ}-120^{\circ} \mathrm{E}\right)$ average of precipitation.

The model shows apparent bias in the northwestern Pacific. In the observations, as a result of the northwestward extension of the Inter-tropical Convergence Zone (ITCZ), there exists a strong rainfall center over the tropical northwestern Pacific. However, this center is missing in the simulation. A similar bias is also seen in other versions of the GAMIL model [20,32], which may be a result of the deficiency in the convection scheme.

To reveal the leading mode of EASM inter-annual variabilities, a combined Empirical Orthogonal Function (EOF) analysis was performed for the summer (May to September, MJJAS) mean precipitation and $850-\mathrm{hPa}$ winds over East Asia. As shown in Figure 9, on the east of $100^{\circ} \mathrm{E}$, the precipitation anomalies feature an out-of-phase change between North China and the Yangtze River valley. Excessive rainfall is seen in North China, while deficient rainfall occures along the middle-lower reaches of the Yangtze River valley. This pattern is similar to that in the observation [33]. Corresponding to the rainfall anomalies, the $850-\mathrm{hPa}$ wind anomalies feature a strong anticyclone over the East Asian monsoon region. The above characteristics are evident in the leading modes of the MWP, LIA, $20 \mathrm{CW}$ and the control experiments, except for the slight differences in the meridional position of the anticyclone and the associated precipitation anomalies. Since the climate backgrounds of the MWP, LIA and 20CW are different from each other, the similarities of the leading interannual variability mode among the three periods indicate that the impact of climate backgrounds on the interannual variabilities of the EASM is negligible. The similarities among three different periods and their resemblances to the pre-industrial control run indicate that the leading mode is actually an internal mode of the coupled climate system, and that the influence of the external forcing agents (e.g. solar constant, GHGs, sulfate aerosols) is not significant.

Previous studies suggested that the mean climate difference between the MWP and LIA periods might impact on the interannual variability mode, which further modifies the relationship between the mid-latitude (north of $40^{\circ} \mathrm{N}$ ) and the tropical-subtropical precipitation changes over East Asia [34]. However, this phenomenon was not significant in our study, suggesting that it may be model-dependent. Multimodel inter-comparisons are needed in the future to investigate this variation.

Although the spatial patterns of rainfall and wind anomalies associated with the leading interannual variability mode of the East Asian monsoon are nearly the same in the MWP, LIA, 20CW, and pre-industrial control experiments, differences are seen in the dominant time periods of the corresponding principal component (PC) time series. Spectral analysis is performed on the PC time series. As shown in the bottom panel of Figure 9, the spectrum exhibits two peaks in the warm period (i.e. a major 5-year peak and a secondary 3-year peak in the MWP experiment; a major 4.5-year peak and a secondary 2.5-year peak in the $20 \mathrm{CW}$ experiment). The 2.5-3 year peak is a manifestation of quasibiannual oscillation of the East Asian summer monsoon [33]. During the cold period, i.e. the LIA and the pre-industrial 

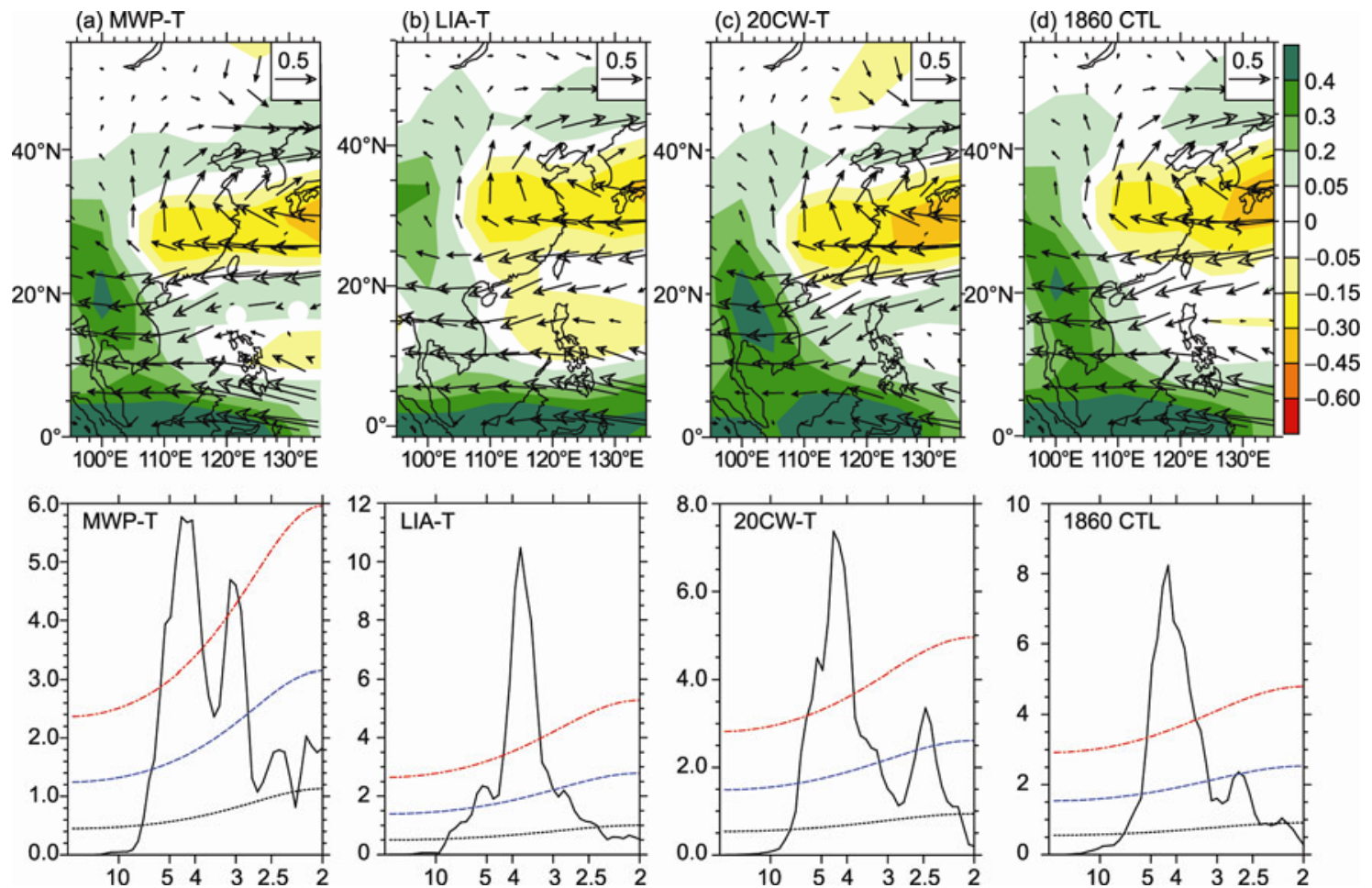

Figure 9 The leading inter-annual variability mode of the East Asian summer monsoon (upper panel, where shading is precipitation anomaly in mm/d; the vectors are wind anomalies at $850 \mathrm{hPa}$ in $\mathrm{m} / \mathrm{s}$ ), and the spectra of the corresponding principal component time series (bottom panel, the unit of abscissa is year; the colored lines from the upper to the lower denote a significant test at $1 \%, 2.5 \%$ and $5 \%$ levels, respectively).

control experiment, the spectrum only exhibits one peak around 4-year, while the quasi-biannual oscillation is not significant. The above differences suggest that the quasibiannual oscillation of the East Asian summer monsoon [35-37] tends to be more prevalent in the warmer climate.

\subsection{Comparison of the internal and external modes of East Asian summer monsoon precipitation}

In the past millennial climate simulation, variability modes of the East Asian summer monsoon can be separated into external and internal modes. The external mode is driven by the external forcing agents, including solar activities and volcanic eruptions, while the internal mode is the result of the interaction of the coupled ocean-atmosphere-land surface-sea ice system [34]. The external mode can be identified by calculating the mean state difference between the MWP and LIA periods. Since the difference is caused by the changes of effective solar radiation, this mode is defined as "external mode".

Following the previous study [34], the internal mode is identified in the following manner. First, based on the outputs of the long-term pre-industrial control simulation, we calculate the regional average of MJJAS (from May to September) mean precipitation within the East Asian Meiyu area $\left(21^{\circ}-35^{\circ} \mathrm{N}, 105^{\circ}-120^{\circ} \mathrm{E}\right)$ and then obtain the time series. Second, we generate the composite analysis of the precipitation time series. The threshold of composite analysis is one standard deviation of the normalized time series. The corresponding 850-hPa wind anomalies are also calculated.

As shown in Figure 10, the external mode features a weak anticyclone over the east of $110^{\circ} \mathrm{E}$, and the East Asian continent is controlled by weak anomalous southerlies. The corresponding rainfall anomalies over the east of $110^{\circ} \mathrm{E}$ exhibit coherent changes between south and north. Wind anomalies associated with the internal mode are nearly the same as those of the leading interannual variability mode, with a strong anticyclone south of $35^{\circ} \mathrm{N}$ over the East Asiawestern Pacific region, and a cyclonic circulation north of $35^{\circ} \mathrm{N}$ and east of $110^{\circ} \mathrm{E}$. The corresponding rainfall anomalies exhibit excessive rainfall in the north, and deficient rainfall in the south (i.e. a meridional out-of-phase change of rainfall).

How to understand the monsoon circulation anomalies associated with the external and internal modes? East Asian summer monsoon circulation is driven by the large scale land-sea thermal contrasts. The SAT distributions associated with the external and internal modes are compared in Figure 10(c), (d). Following the external mode, there is a coherent warming over the East Asian continent. The increase of effective solar radiation leads to a stronger warming over the middle and high latitudes of the East Asian continent compared to the lower latitudes. Meanwhile, stronger warming is seen the land than the ocean. Thus, the above temperature response suggests an enhanced land-sea thermal contrast. In addition, a warm low pressure area forms 
(a) MWP-LIA

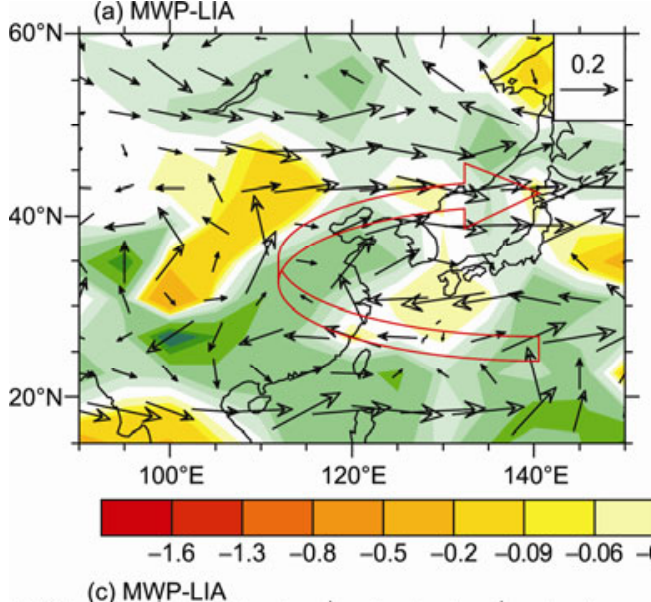

(b) CNTL

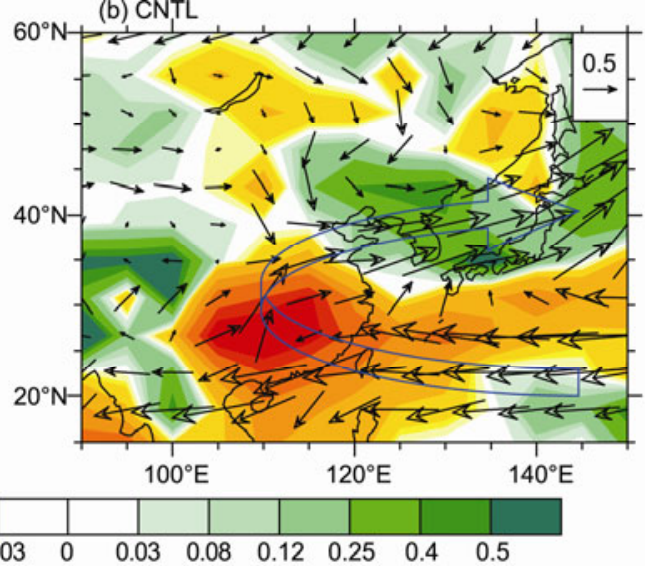

(d) CNTL
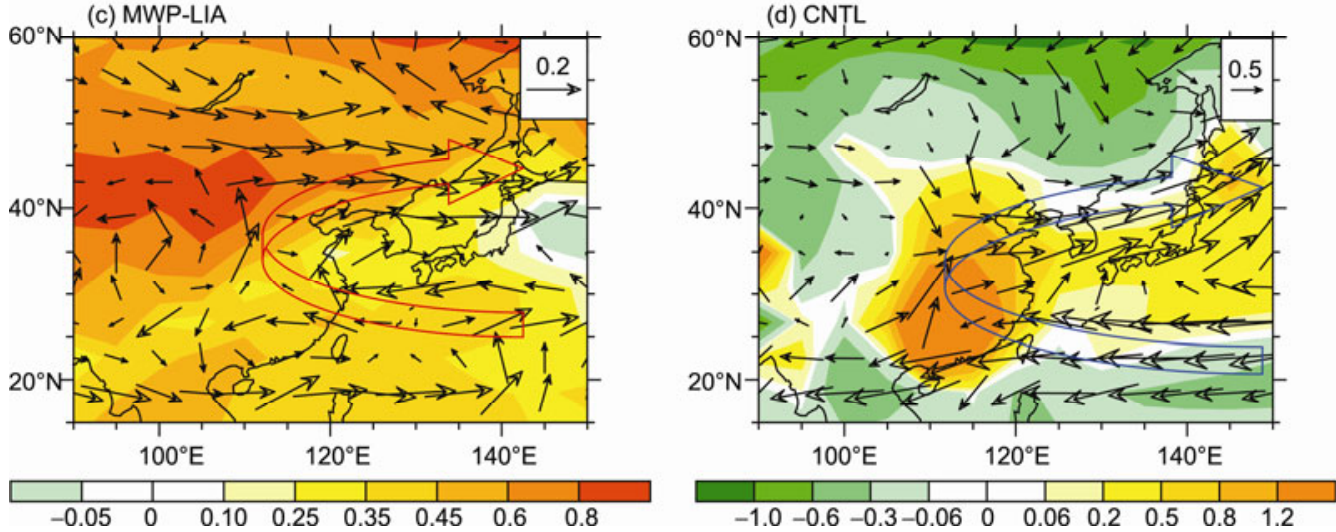

Figure 10 External mode ((a), (c)) and internal mode ((b), (d)) of the East Asian summer monsoon (upper panel, shading is rainfall anomaly in unit of $\mathrm{mm}$ /day; bottom panel, shading is surface air temperature anomaly in unit of $\mathrm{K}$; vectors are wind anomalies at $850 \mathrm{hPa}$ in unit of $\mathrm{m} / \mathrm{s}$ ). The external mode ((a),(c)) is calculated as the difference between the MWP and LIA experiments. The internal mode ((b), (d)) is based on composite analysis of the time series of regional $\left(21^{\circ}-35^{\circ} \mathrm{N}, 105^{\circ}-120^{\circ} \mathrm{E}\right)$ average of MJJAS precipitation anomalies. The threshold of composite analysis is one standard deviation of the normalized time series.

over the middle and high latitudes, and the zonal pressure gradient along the East Asian continent increases. As a result, it results in stronger south wind anomalies over the north of $25^{\circ} \mathrm{N}$ (Figure $10(\mathrm{c})$ ).

The temperature anomalies associated with the internal mode appears as a local warming east of $105^{\circ} \mathrm{E}$ and between $20^{\circ}-40^{\circ} \mathrm{N}$. The warming center is surrounded by cold anomalies in the meridional direction (Figure 10(d)). The pattern of temperature anomaly is dominated by condensational heating associated with local rainfall changes (Figure 10(b)). The rainfall anomaly is dominated by circulation change remotely forced by ENSO events in the equatorial eastern Pacific [38-40].

The global SAT anomalies associated with external and internal modes are shown in Figure 11. For the external mode (Figure 11(a)), the temperature anomaly features a coherent warming over the northern hemispheric land area, and the warming over the ocean area near the eastern parts of the Asian continent is not significant. Temperature anomalies indicate an enhanced land-sea thermal contrast, and thereby stronger summer monsoon circulation. For the internal mode (Figure 11(b)), the temperature change exhibits colder anomalies over the equatorial eastern Pacific [10], demonstrating that the inter-annual variability of this region is a forcing mechanism for the internal mode of monsoon variability.

Previous studies have shown that the FGOALS_gl model has a reasonable performance in simulating the ENSO variabilities, which is a natural variability mode of the coupled climate system [25]. Under the external forcing of solar variabilities and volcanic eruptions, it seems that this model is unable to reproduce the centennial scale variations of ENSO events [41]. East Asian summer monsoon can be influenced bye ENSO events through tele-connections. The internal mode of monsoon variability is dominated by the changes of the equatorial eastern Pacific sea surface temperatures. The centennial scale variability of the monsoon is driven by the land-sea thermal contrast change, which results from the response to the specified external effective solar radiation changes, while the contributions from ENSO are small.

\section{Summaries and discussions}

With the aim to reveal the differences among the Medieval 


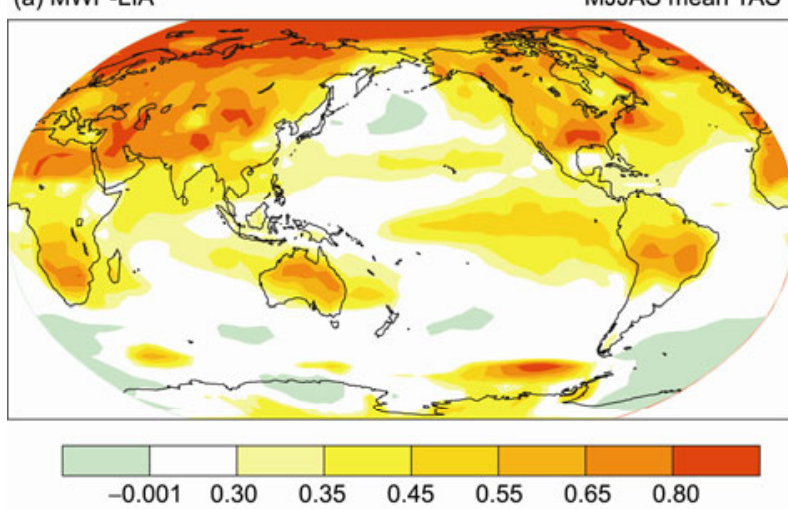

(b) CNTL
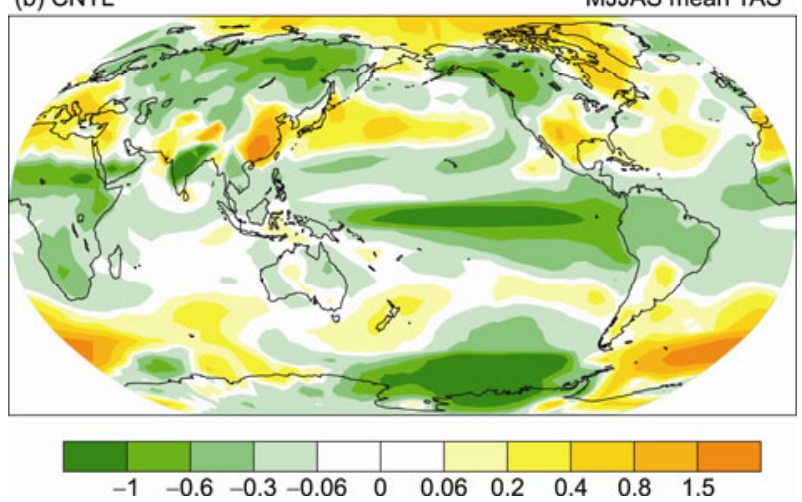

Figure 11 Surface air temperature anomalies associated with the external mode (a) and internal mode (b) of East Asian summer monsoon variability (Units: K).

Warm Period (MWP), Little Ice Age (LIA), and 20th century global warming (20C), six sets of transient and equilibrium simulations are performed using the climate system model FGOALS_gl, which was developed by LASG/IAP. The model is driven by the reconstructed solar variabilities, volcanic eruptions, GHGs and sulfate aerosol. The main results are summarized below:

(1) Relative to the pre-industrial control run, the MWP experiment exhibits a warming of $0.40^{\circ} \mathrm{C}$ over most parts of the globe, except for the mid-latitude North Pacific and Eurasian continent. The warming center is located in the high latitudes of northern America, with the magnitude of $1.0^{\circ} \mathrm{C}$. Both the MWP and $20 \mathrm{CW}$ experiments exhibit a polar amplification response. The warm anomalies in the high latitudes of the Northern Hemisphere are stronger than those in the Southern Hemisphere. The magnitude of the natural warming during the MWP is weaker than that during the 20 th century.

(2) Relative to the pre-industrial control run, the LIA cooling is evident in most parts of the globe, with the strongest cooling over the high latitude Eurasian continent, where the cooling center is stronger than $-1.0^{\circ} \mathrm{C}$. The Atlantic temperature changes over the north (south) of the equator exhibit colder (warmer) anomalies. Warm anomalies are seen over the high latitudes in the northern Ameri- can continent. The maximum cooling of the LIA appears over the polar area of the Northern Hemisphere. The cooling is mainly located in the lower troposphere.

(3) The MWP and the 20CW experiments show similar vertical structures of temperature changes. The zonal mean temperatures exhibit the strongest warming in the middle troposphere around $200-300 \mathrm{hPa}$. The strongest warming of the MWP is $0.50^{\circ} \mathrm{C}$, while that of the $20 \mathrm{CW}$ is greater than $1.0^{\circ} \mathrm{C}$. The middle-troposphere amplification of the warm anomalies is the result of tropical convective heating, which is the strongest in the middle troposphere because of the concentration of water vapor. The LIA cooling also exhibits a polar amplification characteristic.

(4) The equilibrium and transient simulations show differences in both the spatial pattern and the intensity of temperature anomalies. The difference is the most evident in the MWP and LIA period. The natural warming of the MWP simulated by the transient experiment covers a larger area, and is also stronger in the intensity than that in the equilibrium experiment. The cold anomalies of the LIA simulated by the transient experiment are also stronger than those of the equilibrium experiment. The same-sign-rates between the simulation and the reconstruction during the warm periods are generally higher than those during the cold periods.

(5) The tropical precipitation response is forced by the sea surface temperature anomalies. During the MWP and $20 \mathrm{CW}$, there are significant positive precipitation anomalies along $10^{\circ} \mathrm{N}$. During the LIA, there are significant negative precipitation anomalies along the equator. The climate backgrounds show no significant impacts on the leading mode of the EASM inter-annual variability. During the MWP, LIA, and $20 \mathrm{CW}$, the interannual variability mode all feature an out-of-phase changes in precipitation between the Yangtze River Valley and North China. However, the dominant time periods of the leading mode are modulated by the climate backgrounds, and the biannual oscillation of the EASM tends to be more prevalent in warmer climate periods.

(6) Within a centennial time scale, the external mode driven by the changes of the effective solar radiation exhibits a coherent variation of precipitation over the east of $110^{\circ} \mathrm{E}$ between the Yangtze River Valley and North China. The external mode is dominated by the large scale land-sea thermal contrast change. The internal mode is produced by internal variability of the coupled climate system (i.e. ENSO events), and features an out-of-phase variation of precipitation between the Yangtze River Valley and North China.

In this research, the MWP, LIA, and 20th century warming are simulated by the coupled climate system model of LASG/IAP. Major differences among three typical time periods of the last millennium are compared. Although a model-reconstruction comparison indicates that the model can reasonably reproduce the large scale temperature changes, further studies are needed to identify the reliability of the simulation in reproducing the regional characteristics of the past climate change. In the international climate modeling 
community, the past millennial climate simulation is still in its infancy. In comparison with the $6 \mathrm{ka}$ BP mid-Holocene and $21 \mathrm{ka}$ BP Last Glacial Maximum simulation coordinated by PMIP, the last millennial climate simulation is even more difficult. This is because the external forcing changes during the last millennium are far weaker than those in the mid-Holocene and the Last Glacial Maximum. The weak change of external forcing is a challenge for the model to response. For example, when driven by identical external forcing agents, including solar constant and volcanic eruptions, the global and Northern Hemispheric average of SAT changes simulated by different climate models agree well with the reconstruction. However, a large spread is seen in the regional patterns of temperature changes simulated by different models $[42,43]$. With the aim to reduce model uncertainties, the CLIVAR/PAGES joint working group has promoted international collaborations in multi-model intercomparisons and past climate record reconstructions. Coordinated by PMIP for IPCC AR5, many climate modeling centers around the world will perform the last millennial climate simulation. The LASG/IAP climate system model will be involved in this modeling activity, and the results presented here will provide a useful reference for the ongoing long-term transient simulation.

Finally, the model-dependence of the results presented here needs to be examined in future studies. Based on the simulation of the LASG/IAP climate system model, we have revealed past millennial climate changes. Results are consistent with previous modeling studies in global, hemispheric and continental scale temperature changes [6,7]. However, differences are also seen in regional patterns of temperature changes. The difference may be the result of uncertainties in the reconstruction of external forcing data, model bias, and also uncertainties in the reconstruction. Multi-model inter-comparisons based on the outputs of the last millennial climate simulation coordinated by PMIP for IPCC AR5 should help us reduce model uncertainties.

This work was supported by the National Natural Science Foundation of China (40890054).

1 Wang S W, Xie Z H, Cai J N, et al. Study on the global mean temperature changes during the last millennium (in Chinese). Prog Nat Sci, 2002, 12: 1145-1149

2 Solomon S D, Qin M, Manning Z, et al. IPCC, Climate Change 2007: The Physical Science Basis, ed. Contribution of Working Group I to the Fourth Assessment Report of the Intergovernmental Panel on Climate Change. Cambridge: Cambridge University Press, 2007

3 Ge Q S, Zheng J Y, Man Z M, et al. Reconstruction and analysis on the series of winter-half-year temperature changes over the past 2000 years in Eastern China (in Chinese). Earth Sci Front, 2002, 9: 169-181

4 Wang S W, Gong D Y. Temperature change in several typical periods of Holocene in China (in Chinese). Nat Sci Prog, 2000, 10: 325-332

5 Zhou T J, Man W M, Zhang J. Progress in numerical simulations of the climate over the last millennium (in Chinese). Adv Earth Sci, 2009, 24: 469-476

6 Liu J, Chen X, Wang S M, et al. Palaeoclimate simulation of the Lit- tle Ice Age (in Chinese). Prog Nat Sci, 2004, 14: 462-468

7 Chen X, Liu J, Wang S M. Climate simulation of Little Ice Age over Eastern Asia (in Chinese). Sci Meteorol Sin, 2005, 25: 1-8

8 Zhou J S, Yu Y Q, Liu H L, et al. Progress in the development and application of climate ocean models and ocean-atmosphere coupled models in China. Adv Atmos Sci, 2007, 24: 1109-1120

9 Zhou T J, Yu R C. Twentieth century surface air temperature over China and the globe simulated by coupled climate models. J Clim, 2006, 19: 5843-5858

10 Man W M, Zhou T J, Zhang J, et al. The 20th century climate simulated by LASG/IAP climate system model FGOALS_gl (in Chinese). Acta Meteorol Sin, 2011, 69: 644-654

11 Liu J, von Storch H, Chen X, et al. Comparison of simulated and reconstructed temperature in Eastern China during the last millennium (in Chinese). Chinese Sci Bull, 2005, 50: 2251-2255

12 Liu J, von Storch H, Chen X, et al. Long-time modeling experiment on global climate change for the last millennium (in Chinese). Adv Earth Sci, 2005, 20: 561-567

13 Kuang X Y, Liu J, Wang H L, et al. Comparison of simulated and reconstructed precipitation in China during the last millennium (in Chinese). Adv Earth Sci, 2009, 24: 159-171

14 Zhang J, Zhou T J, Man W M, et al. The transient simulation of Little Ice Age by LASG/IAP climate system model (in Chinese). Quat Sci, 2009, 29: 1125-1134

15 Man W M, Zhou T J, Zhang J, et al. The equilibrium response of LASG/IAP climate system model to prescribed external forcing of Little Ice Age (in Chinese). Chin J Atmos Sci, 2010, 34: 914-924

16 Zhou $\mathrm{T}$ J, Wang Z Z, Yu R C, et al. The climate system model FGOALS_s using LASG/IAP spectral AGCM SAMIL as its atmospheric component (in Chinese). Acta Metrorol Sin, 2005, 63: 702-715

17 Zhou T J, Yu R C, Wang Z Z, et al. The Atmospheric General Circulation Model SAMIL and the Corresponding Coupled Climate System Model FGOALS_s (in Chinese). Beijing: Meteorological Press, 2005. 288

18 Yu Y Q, Zhi H, Wang B, et al. Coupled model simulations of climate changes in the 20th century and beyond. Adv Atmos Sci, 2008, 25: $641-654$

19 Zhou T J, Wu B, Wen X Y, et al. A fast version of LASG/IAP climate system model and its 1000-year control integration. Adv Atmos Sci, 2008, 25: 655-672

20 Wen X Y, Zhou T J, Wang S W, et al. Performance of a reconfigured atmospheric general circulation model at low resolution. Adv Atmos Sci, 2007, 24: 712-728

21 Crowley T J. Causes of climate changes over the past 1000 years. Science, 2000, 289: 270-277

22 Xie P P, Arkin P A. Global precipitation: A 17-year monthly analysis based on gauge observations, satellite estimates, and numerical model outputs. Bull Amer Meteorol Soc, 1997, 78: 2539-2558

23 Dai A G, Wigley T M L, Boville B A, et al. Climates of the 20th and 21st centuries simulated by the NCAR Climate System Model. J Clim, 2001, 14: 485-519

24 Manabe S, Wetherald R T. Thermal equilibrium of the atmosphere with a given distribution of relative humidity. J Atmos Sci, 1967, 24 : 241-259

25 Man W M, Zhou T J, Zhang L X. The tropical Pacific interannual variability simulated by LASG/IAP climate system model FGOALS_gl (in Chinese). Chin J Atmos Sci, 2010, 34: 1141-1154

26 Qian Y F, Zhou T J. Modelling tests of the error subtraction scheme for the pressure gradient force in models with topography (in Chinese). Plateau Meteorol, 1995, 14: 1-9

27 Qian Y F, Zhou T J. Error subtraction method in computing pressure gradient force for high and steep topographic areas (in Chinese). J Tropical Meteorol, 1994, 10: 358-368

28 Yu R C, Li W, Zhang X H, et al. Climatic features related to eastern China summer rainfalls in the NCAR CCM3. Adv Atmos Sci, 2000, 17: 503-518

29 Chen H M, Zhou T J, Neale R B, et al. Performance of the New NCAR CAM3.5 in East Asian Summer Monsoon simulations: Sensitivity to modifications of the convection scheme. J Clim, 2010, 23: 3657-3675 
30 Zhou T J, Li Z X. Simulation of the east Asian summer monsoon by using a variable resolution atmospheric GCM. Clim Dyn, 2002, 19: $167-180$

31 Zou L W, Zhou T J, Li Z X, et al. East China summer rainfall variability of 1958-2000: Dynamical downscaling with a variable-resolution AGCM. J Clim, 2010, 23: 6394-6408

32 Li L J, Wang Y Q, Wang B, et al. Sensitivity of the grid-point atmospheric model of IAP LASG (GAMIL1.1.0) climate simulations to cloud droplet effective radius and liquid water path. Adv Atmos Sci, 2008, 25: 529-540

33 Zhou T J, Yu R C. Atmospheric water vapor transport associated with typical anomalous summer rainfall patterns in China. J Geophys Res, 2005, 110: D08104, doi:10.1029/2004JD005413

34 Liu J, Wang B, Wang H L, et al. Forced response of the East Asian summer rainfall over the past millennium: Results from a coupled model simulation. Clim Dyn, 2010, doi: 10.1007/s00382-009-0693-6

35 Shen S, Lau K M. Biennial oscillation associated with the East Asian summer monsoon and tropical Pacific sea surface temperature anomalies. J Meteorol Soc Jpn, 1995, 73: 105-124

36 Chang C P, Zhang Y S, Li T. Interannual and interdecadal variation of the East Asian summer monsoon and tropical Pacific SSTs. J Clim, 2000, 13: 4310-4340

37 Huang R H, Chen J L, Huang G, et al. The quasi-biennial oscillation of summer monsoon rainfall in China and its cause (in Chinese). Chin J Atmos Sci, 2006, 30: 545-560

38 Wang B, Wu R G, Fu X H. Pacific-East Asian teleconnection: How does ENSO affect East Asian climate? J Clim, 2000, 13: 1517-1536

39 Wang B, Zhang Q. Pacific-East Asian teleconnection. Part II: How the Philippine Sea anomalous anticyclone is established during El Niño development. J Clim, 2002, 15: 3252-3265

40 Wu B, Zhou T J, Li T. Seasonally evolving dominant interannual variability modes of East Asian Climate. J Clim, 2009, 22: 2992-3005

41 Man W M, Zhou T J. Forced response of atmospheric oscillations during the last millennium simulated by a climate system model. Chinese Sci Bull, 2011, 56: 3042-3052

42 Widmann M, Tett S F B. Simulating the climate of the last millennium. IGBP Newslett, 2004, 56: 10-13

43 Shindell D T, Schmidt G A, Mann M E, et al. Solar forcing of regional climate change during the Maunder Minimum. Science, 2001, 294: 2149-2152

Open Access This article is distributed under the terms of the Creative Commons Attribution License which permits any use, distribution, and reproduction in any medium, provided the original author(s) and source are credited. 